\title{
Time perspective influence on management leadership styles and the mediating role of self-efficacy
}

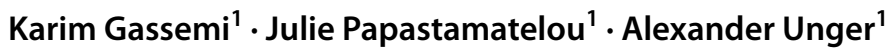

Received: 8 July 2020 / Accepted: 26 December 2020 / Published online: 10 February 2021

(c) The Author(s) 2021

\begin{abstract}
We examined if time perspectives (TP) and the Deviation from a Balanced Time Perspective (DBTP—cf. Stolarski et al. Time Soc 20(3):346-363, 2011) have an effect on four types of Leadership Styles. Based on previous studies it was observed, that Self-Efficacy (SE) is determined by time perspectives (Epel et al. J Appl Soc Psychol 29(3):575-596, 1999). In particular, the transformational and transactional leadership styles could depend on higher self-efficacy of managers. We additionally tested if general self-efficacy (GSE) mediates the influence of time perspectives and the Deviation from a Balanced Time Perspective on Leadership Styles. We recruited a sample of former MBA-students, who now work in the middle management of German companies. We used the zimbardo time perspective inventory (ZTPI; Zimbardo and Boyd J Pers Soc Psychol 77(6):1271-1288, 1999), the Multifactor Leadership Questionnaire (MLQ) by Felfe and Goihl (Deutsche überarbeitete und ergänzte Version des Multifactor Leadership Questionnaire (MLQ) [German revised and extended version of the Multifactor Leadership Questionnaire (MLQ)], Zentrum für Umfragen Methoden und Analysen, Mannheim, 2002) and the general self-efficacy-scale by Schwarzer and Jerusalem (Generalized Self-Efficacy scale, Nfer-Nelson, Windsor, 1995). Past Positive orientation has no significant effect on any of the four leadership styles. The present hedonistic dimension enhances and the past negative orientation reduces the transformational leadership style. The present fatalistic orientation reduces the Transformational and transactional leadership styles, but enhances the laissez-faire leadership style. Moreover, future enhances the transformational and transactional leadership styles. DBTP reduces the transformational and transactional leadership styles. The mediator role of GSE was confirmed for the transformational and transactional leadership style. Managers' time perspectives are important for implementing an efficient leadership style.
\end{abstract}

Keywords Time perspectives $\cdot$ Leadership styles $\cdot$ Managers $\cdot$ Self-efficacy

\section{Introduction}

Time perspectives (TP) have been shown in several studies to be highly relevant for cognitive, motivational and emotional elements of human thinking and behavior. One measurement operationalization that has been intensively used in the last twenty years is the zimbardo time perspective inventory (ZTPI). This scale was developed by Zimbardo and Boyd (1999) and differentiates between five independent dimensions of time as a reference system. These five time perspectives are: past negative, past positive, present hedonistic, present fatalistic and future. Past negative refers

Julie Papastamatelou

jpapas@gmx.net

1 University of Business \& Society Ludwigshafen,

Ludwigshafen, Germany to negative past experiences, including those of one's childhood and to their effect on the present life (Zimbardo and Boyd 1999). This time perspective is related to feelings of regret and pain. Individuals are afraid of experiencing negative events of the past once again. According to Holman and Zimbardo (2009) a too pronounced past negative orientation can lead to impaired social interactions, and conflicts in relationships.

Past Positive is connected to a nostalgic and positive interpretation of the past, which enhances the recall of positive memories (Zimbardo and Boyd 1999). If this Time Perspective is too pronounced, it can lead to less concentration in the present and future. The Present Hedonistic orientation, measures the tendency of an individual to strive for immediate gratification and enjoyment of present life. It refers to an adventurous type of living, through avoidance of routine and boredom. If this Time 
Perspective is too pronounced it can lead to taking risks without considering negative consequenses (Boniwell and Zimbardo 2003). Present Fatalistic is related to the degree the individual assumes that his life is determined by external forces (Gonzalez and Zimbardo 1985; Zimbardo and Boyd 1999). This Time Perspective is associated with low self-esteem, helplessness and pessimism. If Present Fatalism is too pronounced, it can lead to anxiety (Papastamatelou et al. 2015), and post-traumatic stress disorder (Zimbardo et al. 2012). Finally, Future refers to the idea of working intensively in the present, in order to achieve high-standard goals in the future. It is associated with hard work and self-control. If this Time Perspective dimension is too pronounced, it can lead to missing the joy of the present.

\subsection{Balanced time perspective and deviation from a balanced time perspective}

One central concept in the time perspective research is the idea that specific combinations of time perspectives can be balanced or unbalanced, based on assumed optimum scorings on the individual time perspectives (cf. Rönnlund and Carelli 2018; Stolarski 2016; Stolarski et al. 2016). One of the concepts (cf. Stolarski et al. 2011) of the balanced time perspective (BTP) operationalizes the measurement of the deviation from the BTP (DBTP). According to Stolarski et al. (2011, 354), in order to reach a BTP one should score highly on the past positive dimension ( $\mathrm{PP}=4.60)$, moderate highly on the present hedonism orientation $(\mathrm{PH}=3.90)$, moderate highly on the Future perspective $(F=4.00)$, and weak on the past negative $(\mathrm{PN}=1.95)$ and the present fatalistic orientations $(\mathrm{PF}=1.50)$.

The relationship between Time Perspectives and a wide range of different domains, such as academic achievement (Barber et al. 2009; Gutiérrez-Braojos 2015), well-being (Boniwell et al. 2014; Drake et al. 2008) or stress coping (Blomgren et al. 2016; Olivera- Figueroa et al. 2015; Papastamatelou et al. 2015; Rönnlund et al. 2018) has already been examined. However, there are only a few studies dealing with workplace related questions, such as the influence of Time Perspectives on working attitudes or working satisfaction (Korff et al. 2017; Wojtkowska et al. 2019), on violations of business ethics (Unger et al. 2019) or on burnout proneness (Papastamatelou and Unger 2018). In particular studies about the association between Time Perspectives of Managers and their leadership styles are missing in the literature.

The current study was conducted to close this gap and to examine the importance of Time Perspectives for managers and their leadership styles, as well as to investigate the role of self-efficacy of leaders.

\subsection{Leadership}

In the process of leadership, a group is being influenced by an individual with the aim to reach a common goal (Northhouse 2016). The style of a leader is the way in which he provides guidance and motivates employees. Therefore, leadership is an important factor in determining success of a company in today's competitive environment. A leadership style refers to the way in which team managers try to improve results and performance within a team (Anit 2006).

\subsection{Self-efficacy and time perspectives}

Self-efficacy refers to a belief in one's abilities to draft and implement action plans, which are necessary for reaching specific goals (Bandura 1997). General self-efficacy measures the individual differences in the views of the own capability in completing working tasks. General selfefficacy considers the belief that one is able to deliver a good performance in different contexts. With respect to leaders, general self-efficacy would mean that they believe in their potential to lead.

Self-efficacy has been linked to the future time perspective. In order for individuals to be self-efficient, they have to move on from negative past experiences and work toward a future, while considering obstacles as challenges. In addition, research results have indicated that self-efficacy correlates negatively with the Past Negative and the Present Fatalistic dimensions. A concentration toward a negative past and a fatalistic present do not allow a positive evaluation of one's abilities and potential in leading capabilites which could be translated into successful actions (Zebardast 2011, 937).

As the future time perspective is about the orientation toward the future and the reaching of goals (Zimbardo and Boyd 2008), it stands to reason that those scoring high on the Future Time Perspective displayed more success in goal achievement than those scoring low on the Future Time Perspective (Taylor and Wilson 2019).

\subsection{Self-efficacy, leadership and time perspectives}

Leadership self-efficacy refers to the belief of a leader in his ability to lead (Murphy 1992). According to Bandura (1993) increased efficacy is related to high levels of performance. This effect could be attributed to the influence of self-efficacy on individual choice. Individuals who perceive themselves as being highly efficacious with respect to a specific task, will more likely perform this task, they 
will try to reach ambitious goals and increase their performance. The findings of Chemers et al. (2000) suggest that leadership self-efficacy has an increasing effect on leadership effectiveness, which in turn enhances team performance.

The findings of Paglis and Green (2002) demonstrated that managers who displayed higher leadership self-efficacy and thus whose confidence in their abilities was greater, were rated by their subordinates as having made more progress towards organizational change. Therefore, they found them to be more effective leaders. Similarly, in an experimental study Kane et al. (2002) showed that leaders with high selfefficacy, had more ambitious goals, as well as better strategies, which in turn enhanced group performance. In addition, in various studies (e.g. Wisner 2011) the self-efficacy of leaders is associated with increased team performance.

Leaders with higher self-efficacy are expected to be more effective leaders, since they put more efforts to fulfill their roles and to persist in face of obstacles faced.

\subsection{Transactional leadership}

Transactional leadership refers to transactions which regulate the relationship between the leader and his team (Stewart 2006). Thus, transactional leadership focuses on an reciprocal relationship between leaders and their followers (Northouse 2004). Transactional leaders reward their followers with benefits in exchange for good performance. The rewards include provision of good reviews, raises, and promotions. By doing so, they motivate employees to maintain the status quo and to increase their effectiveness (Northouse 2016). On the other hand they also use sanctions, in order to guarantee compliance of the followers with rules.

The research of Turner et al. (1997) suggests that specific behaviors which are inherent in transactional leadership could be associated with enhanced self-efficacy. According to Bass (1998), transactional leadership can be considered as the basis of transformational leadership. We assume that transactional leadership is related to Future orientation, since it is also associated with impoved self-efficacy and that the Deviation from a Balanced Time Perspective decreases the scoring on transactional leadership.

\subsection{Transformational leadership}

Transformational leadership creates awareness and enhances commitment towards the reaching of group specific goals.

These leaders pay attention to the individual employee, encourage new working ways, and coach the followers through the provison of intellectual stimuli. They provide followers with a clear mission statement, they are confident, optimistic, and empower followers to achieve the company's vision. Transformational leadership is based on the intrinsic motivation and the positive development of followers. This leadership is considered to achieve the best outcome, since employees have the chance to develop themselves and to grow (Northouse 2016).

Existing theories support the notion that the self-efficacy of a leader could be associated to behaviors which are characteristic to transformational leadership.

While only a few studies have examined the relationship between self-efficacy of leaders and transformational leadership style (e.g. Fitzgerald and Schutte 2010; Quigley 2003), the findings indicate that a leader with increased selfefficacy will display an enhanced tranformational leadership style. Transformational leadership is traditionally related to challenges for the status quo and to confidence of followers in their own abilities. Because of the relationship between the transformational leadership style and the self-efficacy of leaders, we assume an association of the transformational leadership style with a pronounced Future dimension. In contrast, we assume that the Deviation from a Balanced Time Perspective decreases the scoring on transformational leadership.

\subsection{Management-by-exception}

Management by exception leadership is about monitoring performance and pusue corrective actions whenever necssary. Management-by-exception concentrates on setting standards and on the compliance of employees with these standards (Judge and Bono 2000). While management-byexception-passive does not provide interventions, which could foster a significant change in business environments, management-by-active-exception is characterized by leaders who actively follow the rules and intervene before problems occur (Aslan et al. 2011, 631).

Moreover, self-efficacy does not seem to be associated with management-by-exception leaders. Since managementby-exception leaders try to enforce working rules, we assume that this leadership style, will nonetheless be enhanced by the Future dimension.

\subsection{Laisse-faire}

According to Bass and Avolio (1990) laissez-faire leadership can be described as the absence of leadership. This style has been found to be less effective compared to the 
transformational and transactional leadership styles (Goodnight 2004). Thus, laissez-faire leaders tend to lead as having no responsibility. In this case the leader invests less effort to meet work related tasks and displays minimal effort to complete tasks (Einarsen et al. 2007).

Laissez-faire leaders do not enable their followers to develop themselves (Northouse 2004). We hypothesize that the fatalistic orientation will foster this leadership style.

On the basis of the theory we have formulated the following hypotheses:

\section{Hypotheses}

Hypothesis 1 The Future dimension will enhance the transformational and transactional leadership styles. The Fatalistic orientation will foster the laisse fair leadership style, whereas the Future dimension will enhance management-by-exception.

Hypothesis 2 The DBTP will reduce the transformational and transactional leadership styles.

Hypothesis 3 Self-efficacy mediates the influence of the DBTP on the transformational and transactional leadership styles.

\section{Methods}

\subsection{Participants}

Our sample consisted of 78 German managers $(n=37$ female, $n=30$ male, 11 without a gender indication with a mean age of $M_{\mathrm{AGE}}=40.52$ years; $\mathrm{SD}=10.27$ years).

All participants have been recruited by the alumni network of a University of Applied Science located in Southwest Germany. The participants were former MBA-students of business-integrated courses, who were recruited through alumni data. The data-collection was conducted by onlinebased questionnaires created by the qualtrics online survey tool. We controlled for the overall response time and each link was case-sensitive and thus, could only be used once.

Participants were informed that the purpose of the study was strictly scientific and anonymity was ensured. After the completion of data-collection, the participants have been debriefed on the research questions of the study.

\subsection{Outcome measures}

In the current study we have used the following measurement instruments:

- The German version of the ZTPI by Reuschenbach et al. (2011).

- The German Multifactorial Leadership Questionnaire (MLQ) by Felfe and Goihl (2002);

- A reduced seven-item version of self-efficacy was used (Schwarzer and Jerusalem 1995).

\subsubsection{Zimbardo time perspective inventory (ZTPI)}

We have used the German version of the ZTPI by Reuschenbach et al. (2011) based on the ZTPI which was developed by Zimbardo and Boyd (1999) as a self-reported questionnaire which consists of 56 items. This questionnaire measures the orientation of individuals towards the five Time Perspectives, namely, past negative, past positive, present hedonistic, present fatalistic and future.

The past-negative subscale contains 10 items which measure regret and negative past experiences. The pastpositive subscale is based on 9 items and measures longing for early life or past times. The present-hedonistic subscale includes 15 items which measure the scores of a participant regarding pleasure-seeking and risk-taking. The presentfatalistic subscale contains 9 items which measure perceived hopelessness towards one's life. The future dimension consists of 13 which measure willingness for work, in order to achieve goals. The 56 statements were rated on a five-point Likert Scale ( $1=$ very unlikely to $5=$ very likely $)$. The scores of each time perspective were formed by the means of the respective dimensions.

\subsubsection{Deviation of the balanced time perspective (DBTP)}

Individuals displaying low scores on past negative and present fatalistic, moderate scores on present hedonistic and high scores on past positive and future are viewed as having reached a Balanced Time Perspective (BTP). For the measurement of the BTP the deviation from the balanced time perspective (DBTP) coefficient was created (Stolarski et al. 2011). This coefficient examines the distance of an individual from the BTP and therefore a bigger distance of a DBTP value from zero, indicates that the individual deviates from a BTP. Following is the formula for the calculation of the DBTP:

$D B T P=\sqrt{(o P N-e P N)^{2}+(o P P-e P P)^{2}+(o P F e P F)^{2}+(o P H-e P H)^{2}+(o F-e F)^{2}}$ 
In this formula $o$ equals the observed value obtained for each measured TP, whereas $e$ equals the expected optimal value for each TP, as indicated by Zimbardo and Boyd [1.95 for past negative (PN), 4.6 for past positive (PP), 1.5 for present fatalistic (PF), 3.9 for present hedonistic $(\mathrm{PH})$, and 4.0 for Future (F)] (Zimbardo and Boyd 2008).

\subsubsection{Multifactor Leadership Questionnaire (MLQ)}

The MLQ was developed by Bass and Avolio (1995). We have used the German version of the MLQ by Felfe and Goihl (2002). It is a 36-item likert-scale with a 5-point response format. According to Bass and Avolio (1994), transformational leadership includes: (1) Idealized Influence, (2) Inspirational Motivation, (3) Intellectual Stimulation and (4) Individualized Consideration.

Idealized influence addresses the role model function of transformational leaders, with which it is possible to sustainably influence employees. A distinction is made between an attributional and a behavioral aspect. The followers show admiration, respect and trust toward the managers (attribution). In addition, the managers have high expectations of their employees and are able to meet these expectations themselves. Their actions are based on ethical and moral principles (behavior-related) (Bass and Avolio 1994).

Inspirational motivation considers the visions of transformational leaders, as well as their ideas on future developments. Leaders show optimism for the future, present a vision, motivte nd encourge followers and explain wht has to be done and why (Uçara et al. 2012, 199).

Intellectual stimulation refers to the encouragement of followers to think creatively and innovatively. Failures are being tolerated and not criticized publicly. Employees are urged to participate and contribute their own ideas, even if they deviate from the ideas of their superiors (Bass and Avolio 1994).

Individualized Consideration considers transformational managers as coaches or mentors for their employees who recognize the personal needs and wishes for performance and growth of their followers. They aim to systematically promote employees and gradually develop their potential (Bass and Avolio 1994).

It is being assumed that transactional leadership is quite effective, but does not cause any special effort and additional commitment, such as the transformational strategies. Transformational leadership is sometimes also used to complement transactional leadership and often increases the effect of transactional leadership on organizational outcomes (Bono and Anderson 2005).

Transactional leadership is being measured by three subscales (Bass and Avolio 1994): Contingent Reward (CR); Management-by-Exception active (MbEa); Management-byException passive (MbEp).
Contingent reward refers to the clarification of mutual expectations between managers and employees. At the same time, appropriate rewards are promised if the expectations are being adequately met (Bass and Avolio 1994).

Management-by-exception active considers managers as the ones who monitor and control processes with regard to errors and correct them if necessary. This strategy is not very effective when it comes to coping with special requirements, but it is quite appropriate in certain situations (Bass and Avolio 1994).

Management-by-exception passive is characterized by extensive reluctance on the part of the manager. They do not make decisions for as long as possible. They only take action when errors or problems make intervention absolutely necessary (Bass and Avolio 1994).

The last subscale refers to the Laissez-faire strategy and shows that transformational leadership is related to Laissez-faire leadership through individualized consideration. Laissez-faire leadership is characterized by passivity and a largely renunciation of leadership and influence. This leadership behavior is not only ineffective for coping with upcoming tasks, but also causes problems itself, because e.g. necessary decisions are delayed (Bass and Avolio 1994). Although Laissez-faire leadership is close to the management by exception passive strategy due to its passive characteristics, the laissez-faire leder does not intervene even after errors occur (Uçara et al. 2012, 199).

According to Bass and Avolio (1994) the scales Management-by-Exception active, Management-by-Exception passive and Laissez-Faire can largely be represented as separate factors/components.

\subsubsection{General self-efficacy (GSE)}

The GSE scale measures the perceived general self-efficacy (Bandura 1993) by a 10-item likert-type scale with a 4-point response format. The German version was validated by Schwarzer and Jerusalem (1995). An example of an item of this scale is: "I can always solve difficult problems if I try hard enough'. Responses categories are: $1=$ Exactly true, $2=$ Moderately true, $3=$ Hardly true, $4=$ Not at all true. For the analyses the scale was reversed, so that a high value represents a high level of self-efficacy.

\subsection{Results}

We have conducted linear regressions to analyze the influence of the individual Time Perspectives on each of the four leadership styles (transformational, transactional, management-by-exception and laissez-faire) which can be examined separately. Management-by-exception active and management-by-exception active have been examined as one leadership style. 
Table 1 Linear regression analysis with the five TP's on transformational, transactional, management-by-exception and Laissez-faire Leadership Style (LS)

\begin{tabular}{llllll}
\hline & $B$ & $S E$ & $\beta$ & $t$ & $p$ \\
\hline Transformational LS: & & & & & \\
Past-positive & -0.05 & 0.09 & -0.06 & -0.51 & 0.305 \\
Past-negative & -0.15 & 0.08 & -0.25 & -1.89 & 0.031 \\
Present-hedonistic & 0.18 & 0.11 & 0.20 & 1.70 & 0.035 \\
Present-fatalistic & -0.21 & 0.10 & -0.28 & -2.05 & 0.022 \\
Future & 0.17 & 0.09 & 0.22 & 1.90 & 0.031 \\
Transactional LS: & & & & & \\
Past-positive & -0.45 & 0.10 & -0.05 & -0.45 & 0.327 \\
Past-negative & -0.09 & 0.09 & -0.14 & -1.02 & 0.157 \\
Present-hedonistic & 0.15 & 0.11 & 0.15 & 1.30 & 0.099 \\
Present-fatalistic & -0.23 & 0.10 & -0.31 & -2.23 & 0.010 \\
Future & 0.22 & 0.10 & 0.27 & 2.31 & 0.012 \\
Management-by-exception LS: & & & & \\
Past-positive & -0.05 & 0.15 & -0.04 & -0.34 & 0.369 \\
Past-negative & 0.16 & 0.13 & 0.19 & 1.23 & 0.111 \\
Present-hedonistic & -0.05 & 0.17 & -0.04 & -0.28 & 0.391 \\
Present-fatalistic & -0.11 & 0.16 & -0.11 & -0.71 & 0.241 \\
Future & 0.24 & 0.14 & 0.22 & 1.66 & 0.051 \\
Past-positive & -0.04 & 0.09 & -0.06 & -0.49 & 0.312 \\
Past-negative & -0.05 & 0.07 & -0.09 & -0.61 & 0.273 \\
Present-hedonistic & 0.05 & 0.10 & 0.07 & 0.55 & 0.262 \\
Present-fatalistic & 0.19 & 0.09 & 0.33 & 2.11 & 0.019 \\
Future & 0.01 & 0.08 & 0.02 & 0.15 & 0.442 \\
\hline & & & & & \\
\hline
\end{tabular}

DBTP deviation from balanced time perspective; for DBTP we conducted separate linear regression analysis including DBTP only

All $p$-values are reported for one-tailed tests

Regarding the transformational leadership style, we observed a significant enhancing effect of Future, $\beta=0.218$ $(5,65), p=0.031$ (all p-values are reported for one-tailed tests). Again, a significant enhancing effect was observed for the present hedonistic dimension, $\beta=0.198(5,65)$, $p=0.035$. Significant reducing effects were instead observed for the past negative, $\beta=-0.251(5,65), p=0.031$, and present fatalistic orientations, $\beta=-0.283(5,65), p=0.022$. Finally, no significant effect was observed for the past positive perspective $(p=0.305)$.

The corresponding regression analysis for the transactional leadership style revealed an enhancing significant of Future orientation, $\beta=0.268(5,67), p=0.012$ and a significant reducing effect of the Present Fatalistic dimension, $\beta=-0.08$ (5, 67), $p=0.010$ (cf. Table 1). The remaining Time Perspectives did not display significant effects (all $p$ 's $>0.0 .98$ ).

For the management-by-exception leadership style, our results indicate only one nearby significant enhancing effect for the Future dimension, $\beta=0.216(5,67), p=0.051$ (cf.
Table 2 Linear regression analysis with the deviation from balanced time perspective (DBTP) on transformational, transactional, management-by-exception and laissez-faire leadership style (LS)

\begin{tabular}{|c|c|c|c|c|c|}
\hline & $B$ & SE & $\beta$ & $t$ & $p$ \\
\hline \multicolumn{6}{|c|}{ Transformational LS: } \\
\hline DBTP & -0.25 & 0.07 & -0.39 & -3.53 & $<0.001$ \\
\hline \multicolumn{6}{|c|}{ Transactional LS: } \\
\hline DBTP & -0.26 & 0.08 & -0.37 & -3.37 & $<0.001$ \\
\hline \multicolumn{6}{|c|}{ Management-By-Exception LS: } \\
\hline DBTP & -0.04 & 0.11 & -0.05 & -0.39 & 0.174 \\
\hline \multicolumn{6}{|c|}{ Laissez-Faire LS: } \\
\hline DBTP & 0.06 & 0.06 & 0.11 & 0.96 & 0.086 \\
\hline
\end{tabular}

All $p$-values are reported for one-tailed tests

Table 1). All other Time Perspectives did clearly fail to reach significance (all $p$ 's $>0.110$ ).

As in the case of management-by-exception, our regression analysis showed that only the Present Fatalistic orientation displayed a significant enhancing effect on the laissez-faire leadership style, $\beta=0.329(5,66), p=0.051$ (cf. Table 1). All other Time Perspectives were not significant (all $p$ 's $>0.272$ ). Therefore, our first hypothesis was confirmed.

Moreover, we have applied the concept of the Deviation from a Balanced Time Perspective (DBTP), as an overall configuration of Time Perspectives and repeated the same regression analyses with DBTP as factor, instead of the individual five Time Perspectives. Our results suggest that DBTP influences the transformational leadership style, $\beta=-0.391(1,69), p<0.001$, as well as the transactional leadership style $\beta=-0.371(1,71), p<0.001$ in a significant reducing way. The more unbalanced the Time Perspective of a manager is, the less pronounced are the transformational and the transactional leadership styles. For both other leadership styles (management-by-exception and laissez-faire leadership style), we did not observe significant effects by the DBTP (cf. Table 2, all $p$ 's $>0.170$ ). Thus, our second hypothesis was also confirmed.

We have examined the role of self-efficacy as a potential mediator of influence of Time Perspectives and DBTP on the leadership styles. Previous work, such as the study by Epel et al. (1999) has already reported that self-efficacy depends on time perspectives. Thus, we have first tested, if the effect of time perspectives and DBTP on self-efficacy could be observed in our sample. For this purpose, we conducted linear regression analyses with the five time perspectives and the DBTP.

For the individual time perspectives, we observed two significant enhancing and one significant reducing effect 
Table 3 Linear regression analysis with the five TP's on general selfefficacy and linear regression analysis with the deviation from balanced time perspective (DBTP) on general self-efficacy

\begin{tabular}{lrllrl}
\hline & \multicolumn{1}{l}{$B$} & SE & $\beta$ & \multicolumn{1}{l}{$t$} & \multicolumn{1}{l}{$l$} \\
\hline Past-positive & 0.05 & 0.08 & 0.07 & 0.58 & 0.141 \\
Past-negative & -0.12 & 0.07 & -0.24 & -1.70 & 0.024 \\
Present-hedonistic & 0.20 & 0.10 & 0.25 & 2.04 & 0.012 \\
Present-fatalistic & -0.07 & 0.09 & -0.12 & -0.82 & 0.104 \\
Future & 0.14 & 0.08 & 0.21 & 1.73 & 0.023 \\
DBTP & -0.48 & 0.63 & -0.36 & -3.27 & $<0.001$ \\
\hline
\end{tabular}

We conducted a separate linear regression analysis for DBTP as independent variable instead of the single five time perspectives

All $p$-values are reported for one-tailed tests

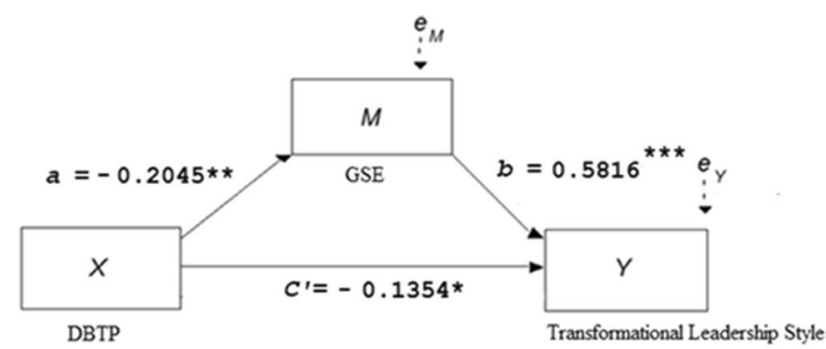

Fig. 1 Mediator model of DBTP on transformational leadership style with general self-efficacy as mediator. $D B T P$ deviation from balanced time perspective, GSE general self-efficacy $(*<0.05, * *<0.01$, and $* * *<0.001)$

on self-efficacy. High scores on the Present Hedonistic $\beta=0.250(5,66), p=0.023$ and Future dimensions, $\beta=0.205$ $(5,66), p=0.045$ enhanced self-efficacy significantly. A reducing effect was observed for the Past Negative orientation, $\beta=-0.235(5,66), p=0.047$. Past Positive and Present Fatalistic were not significant (all $p$ 's $>0.207$ ). Furthermore, the DBTP reduced self-efficacy, $\beta=-0.364$ (1.70), $p<0.001$.
Because the overall configuration of time perspectives as operationalized by the DBTP seemed more relevant than the corresponding individual time perspectives, we have conducted a mediator analysis with DBTP as independent variable, self-efficacy as mediator and leadership styles as dependent variable. For the mediator analysis, we have used the Process Macro by Andrew Hayes for SPSS 24 (Hayes 2013).

The mediation analysis was conducted for each of the four investigated leadership styles, including those for which we have not observed direct effects (management-by-exception and laissez-faire) in the linear regression analyses (Table 3 ).

The first mediation model for the transformational leadership style (cf. Figure 1; Table 4) revealed that the effect of DBTP on the transformational leadership style is partially mediated by general self-efficacy: as assumed the DBTP reduces general self-efficacy significantly ( $a=-0.205$; $p=0.002)$ and general self-efficacy in turn enhances the transformational leadership style significantly $(b=0.582$, $p<0.001)$. Furthermore, the negative direct effect of DBTP on the transformational leadership style remains significant in the mediation model $\left(c^{\prime}=-0.135 ; p=0.047\right)$ : the higher the DBTP the lower the transformational leadership style. The total indirect effect $a+b=-0.119$ reached significance $($ BootLLCI $=-0.2695$; BootULCI $=-0.0222$ ).

With respect to the transactional leadership style (cf. Figure 2; Table 5) we observed that the effect of the DBTP is mediated by general self-efficacy: the DBTP significantly reduces general self-efficacy $(a=-0.204 ; p=0.002)$ and in turn general self-efficacy enhances the transactional leadership style $(b=0.524 ; p<0.001)$. The direct effect reached almost significance in the mediation model $\left(c^{\prime}=-0.149\right.$; $p=0.051$ ), whereas the total indirect effect $a+b=-0.107$ (BootLLCI $=-0.2206$; BootULCI $=-0.0252)$ clearly reached significance.

As reported in the linear regression analysis above, we did not observe a significant effect of DBTP on the management-by-exception leadership style. By conducting the same
Table 4 Regression coefficients, standard errors, and model summary information for the presumed deviation from balanced time perspective (DBTP) influence mediator model with the mediator general self-efficacy (GSE) on transformational leadership style (transform. LS)

\begin{tabular}{|c|c|c|c|c|c|c|c|c|}
\hline \multirow[t]{3}{*}{ Antecedent } & & \multicolumn{7}{|c|}{ Consequent } \\
\hline & & \multicolumn{3}{|l|}{ M (GSE) } & \multicolumn{4}{|c|}{$Y($ Transform. LS) } \\
\hline & & Coeff & $S E$ & $p$ & Coeff & $S E$ & & $p$ \\
\hline X (DBTP) & $a$ & -0.205 & 0.063 & $0.002 c^{\prime}$ & -0.135 & & 0.067 & 0.047 \\
\hline M (GSE) & & - & - & $b$ & 0.582 & & 0.119 & $<0.001$ \\
\hline \multirow[t]{2}{*}{ Constant } & $i_{\mathrm{M}}$ & $\begin{array}{l}3.561 \\
R^{2}=0.132\end{array}$ & 0.144 & $<0.001 \quad i_{\mathrm{Y}}$ & $\begin{array}{l}2.412 \\
R^{2}=0.373\end{array}$ & & 0.448 & $<0.001$ \\
\hline & & \multicolumn{3}{|c|}{$F(1,69)=10.512, p=0.002$} & \multicolumn{4}{|c|}{$F(2,68)=20.198, p<0.001$} \\
\hline
\end{tabular}

$D B T P$ deviation from balanced time perspective, $G S E=$ general self-efficacy $p$-values are for two-tailed tests 


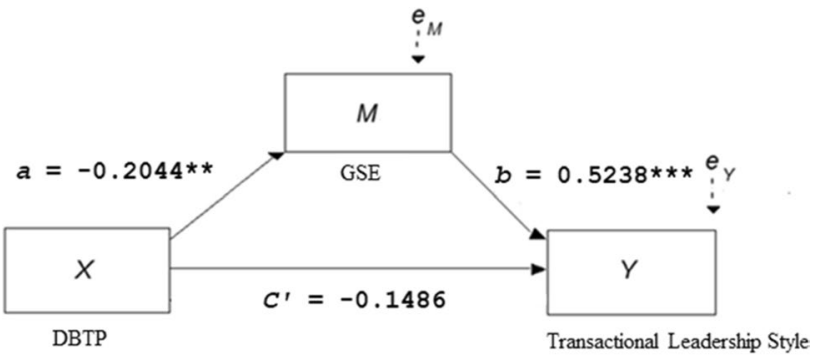

Fig. 2 Mediator model of DBTP on transactional leadership style with general self-efficacy as mediator. $D B T P$ deviation from balanced time perspective, GSE general self-efficacy $(*<0.05, * *<0.01$, and $* * *<0.001)$; the $p$-value for $c^{\prime}$ was in this case $=0.051$

mediation model analysis (cf. Figure 3; Table 6) as for the transformational and the transactional leadership styles, the results showed again that the DBTP reduces general selfefficacy significantly $(a=-0.204 ; p<0.001)$ and general self-efficacy enhances the management-by-exception leadership style $(b=0.445 ; p=0.034)$. The total indirect effect $a+b=-0.091$ reached significance (BootLLCI $=-0.2296$; BootULCI $=-0.0105)$. As in the regression analysis we did not observe a direct effect of DBTP $\left(c^{\prime}=0.045 ; p=0.695\right)$. Thus, the possibility of an indirect mediating effect was confirmed (Fig. 4).

Finally, we did not observe a direct influence of DBTP, nor a significant influence of general self-efficacy on the laissez-faire leadership style (all $p$ 's $>0.464$ ). The total indirect effect $a+b=0.018$ did also not reach significance (BootLLCI $=-0.0185$; BootULCI $=0.0866$ ). Only the reducing effect of DBTP on general self-efficacy was observed, in line with the three preceding mediation analyses $(a=-0.204$; $p=0.002$ ).

Consequently, the laissez-faire leadership style is not affected by DBTP and general self-efficacy and contrary to the other leadership styles, no possible mediation model was found. Our third hypothesis was therefore confirmed (Table 7).

\section{Discussion}

We can summarize that the past negative and present fatalistic perspectives have a negative effect on the transformational leadership style and the present hedonistic and future dimensions have a positive enhancing effect. This result can be explained through the challenges of the status quo by the transformational approach, as it is a more modern leadership style in which the leader is closer to the employees. In addition, this approach focuses on motivating and engaging employees while also having a mutual vision of the future.

The general self-efficacy is of high relevance, in particular for leadership styles, which can be characterized as ambitious and sophisticated, such as the transformational leadership style. This result is in line with reserach supporting the idea that a leader's self-efficacy can be associated to behaviors which are indicating transformational leadership.

According to Bandura (1996) increased efficacy is related to increased performance on various tasks. This could be traced back to the influence self-efficacy has on a personal choice, since individuals who perceive themselves as efficacious will be more likely to choose to perform the particular

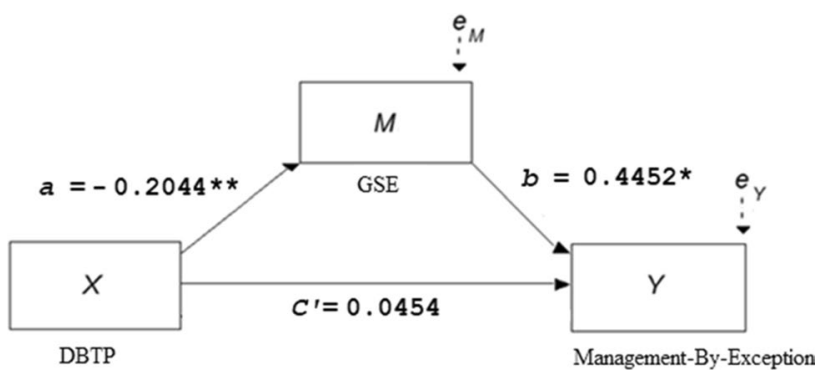

Fig. 3 Mediator model of DBTP on management-by-exception leadership style with general self-efficacy as mediator. DBTP deviation from balanced time perspective, GSE general self-efficacy $(*<0.05$, $* *<0.01$, and $* * *<0.001)$
Table 5 Regression coefficients, standard errors, and modell summary information for the presumed deviation from balanced time perspective (DBTP) influence mediator model with the mediator general self-efficacy (GSE) on transactional leadership style (transactional LS)

\begin{tabular}{|c|c|c|c|c|c|c|c|c|c|}
\hline \multirow[t]{3}{*}{ Antecedent } & & \multicolumn{8}{|c|}{ Consequent } \\
\hline & & \multicolumn{3}{|l|}{$\mathrm{M}(\mathrm{GSE})$} & & \multicolumn{4}{|c|}{$Y($ Transactional LS $)$} \\
\hline & & Coeff & SE & $p$ & & Coeff & SE & & $p$ \\
\hline X (DBTP) & $a$ & -0.204 & 0.063 & 0.002 & $c^{\prime}$ & -0.149 & & 0.075 & 0.050 \\
\hline M (GSE) & & - & - & - & $b$ & 0.524 & & 0.133 & $<0.001$ \\
\hline \multirow[t]{2}{*}{ Constant } & $i_{\mathrm{M}}$ & $\begin{array}{l}3.560 \\
R^{2}=0.132\end{array}$ & 0.143 & $<.001$ & $i_{\mathrm{Y}}$ & $\begin{array}{l}2.655 \\
R^{2}=0.297\end{array}$ & & 0.498 & $<0.001$ \\
\hline & & $F(1,70)=1$ & $=0.002$ & & & & \multicolumn{3}{|c|}{$F(2,69)=14.555, p<0.001$} \\
\hline
\end{tabular}

$D B T P$ deviation from balanced time perspective, GSE general self-efficacy $p$-values are for two-tailed tests 
Table 6 Regression coefficients, standard errors, and modell summary information for the presumed deviation from balanced time perspective (DBTP) influence mediator model with the mediator general self-efficacy (GSE) on management-by-exception leadership style (managementby-exception LS)

\begin{tabular}{|c|c|c|c|c|c|c|c|c|c|}
\hline \multirow[t]{3}{*}{ Antecedent } & & \multicolumn{8}{|c|}{ Consequent } \\
\hline & & \multicolumn{3}{|l|}{ M (GSE) } & & \multicolumn{4}{|c|}{$Y$ (management-by-exception LS) } \\
\hline & & Coeff & SE & $p$ & & Coeff & SE & & $p$ \\
\hline X (DBTP) & $a$ & -0.204 & 0.063 & 0.002 & $c^{\prime}$ & 0.045 & & 0.116 & 0.695 \\
\hline M (GSE) & & - & - & - & $b$ & 0.454 & & 0.205 & 0.034 \\
\hline \multirow[t]{3}{*}{ Constant } & $i_{\mathrm{M}}$ & 3.560 & 0.143 & $<0.001$ & $i_{\mathrm{Y}}$ & 1.635 & & 0.771 & 0.038 \\
\hline & & \multicolumn{4}{|l|}{$R^{2}=0.132$} & \multicolumn{4}{|l|}{$R^{2}=0.066$} \\
\hline & & \multicolumn{4}{|c|}{$F(1,70)=10.663, p=0.002$} & & \multicolumn{3}{|c|}{$F(2,69)=2.439, p=0.095$} \\
\hline
\end{tabular}

$D B T P$ deviation from balanced time perspective, GSE general self-efficacy $p$-values are for two-tailed tests

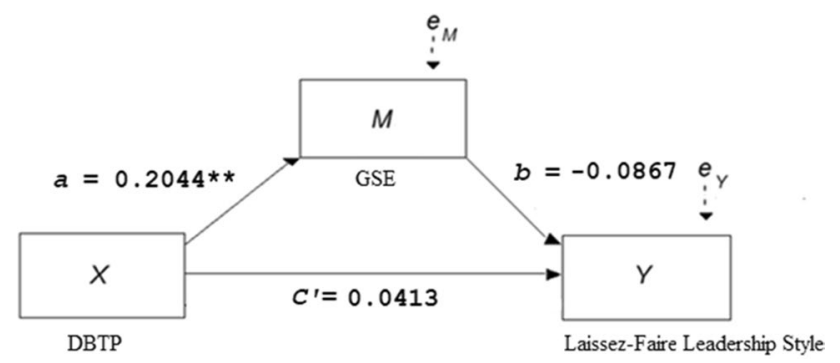

Fig. 4 Mediator model of DBTP on laissez-faire leadership style with general self-efficacy as mediator. $D B T P$ deviation from balanced time perspective, GSE general self-efficacy $(*<0.05$, $* *<0.01$, and $* * *<0.001)$

task, while also setting high performance goals, and in turn display better performance.

Transformational leadership is traditionally associated with instilling confidence in followers that they can achieve higher levels of performance (Kirkpatick and Locke 1991). Thus, it can be assumed that only the ones who perceive themselves as more efficious are able to welcome challenging situations and persuade followers to do the same. Findings on self-efficacy indicate that this construct affects the choices of people regarding goals, expectations, efforts to solve tasks abd persistance when facing of difficulties, hurdles and disappointments (Maurer 2001).

In sum, efficacious individuals are higly motivated, persistent in challenging situations, goal-oriented and clear thinkers under pressure.

Regarding the DBTP we have observed two significant reducing effects on the transformational and the transactional leadership styles. These influences were partly mediated by general self-efficacy. It becomes clear that DBTP hinders the transformational and transactional leadership styles which are the ones associated with self-efficacy.

Moreover, Future orientation increases the scoring of the management-by-exception (nearby significant) and the Present Fatalistic dimension enhances the laissez-faire leadership style.

The influence of time perspectives and DBTP on leadership styles seems plausible, since an individual develops time perspective bevor a specific leadership style is being developed. This study was the first to examine the effects of time perspectives on leadership styles, while also sheding light on mediating role of self-efficacy.

The limitations of this study include in particular the small sample size and the cross-sectional design which doesn't allow to differentiate between cause and effect.
Table 7 Regression coefficients, standard errors, and modell summary information for the presumed deviation from balanced time perspective (DBTP) influence mediator model with the mediator general self-efficacy (GSE) on laissezfaire leadership style (laissezfaire LS)

\begin{tabular}{|c|c|c|c|c|c|c|c|c|}
\hline \multirow[t]{3}{*}{ Antecedent } & & \multicolumn{7}{|l|}{ Consequent } \\
\hline & & \multicolumn{3}{|l|}{ M (GSE) } & & \multicolumn{3}{|c|}{$Y$ (laissez-faire LS) } \\
\hline & & Coeff & $\mathrm{SE}$ & $p$ & & Coeff & SE & $p$ \\
\hline X (DBTP) & $a$ & -0.204 & 0.063 & 0.002 & $c^{\prime}$ & 0.041 & 0.066 & 0.536 \\
\hline M (GSE) & & - & - & - & $b$ & -0.087 & 0.118 & 0.465 \\
\hline \multirow[t]{3}{*}{ Constant } & $i_{\mathrm{M}}$ & 3.560 & 0.143 & $<.001$ & $i_{\mathrm{Y}}$ & 2.464 & 0.443 & $<0.001$ \\
\hline & & \multicolumn{4}{|l|}{$R^{2}=0.132$} & \multicolumn{3}{|l|}{$R^{2}=0.023$} \\
\hline & & \multicolumn{4}{|l|}{$\begin{array}{l}F(1,70)=10.663 \\
\quad p=0.002\end{array}$} & \multicolumn{3}{|c|}{$\begin{aligned} & F(2,69)=0.725, \\
& p=0.488\end{aligned}$} \\
\hline
\end{tabular}

$D B T P$ deviation from balanced time perspective, GSE general self-efficacy $p$-values are for two-tailed tests 
Future research could use longitudinal studies to become more insights into causal effects and rule out alternative ways of causal directions.

Moreover, future studies should also consider other conceptions of leadership styles and include typologies attributed to the style of leadership, in particular the one of Bass (1981) who differentites between production oriented, people oriented, goal achieving or work facilitative.

We can conclude that managers' Time Perspectives are important for implementing an efficient leadership style and that training programs could be developed to improve the Balanced Time Perspectives of managers.

\section{Compliance with ethical standards}

Conflict of interest The authors declare that they have no conflicts of interest.

Open Access Dieser Artikel wird unter der Creative Commons Namensnennung 4.0 International Lizenz veröffentlicht, welche die Nutzung, Vervielfältigung, Bearbeitung, Verbreitung und Wiedergabe in jeglichem Medium und Format erlaubt, sofern Sie den/die ursprünglichen Autor(en) und die Quelle ordnungsgemäß nennen, einen Link zur Creative Commons Lizenz beifügen und angeben, ob Änderungen vorgenommen wurden. Die in diesem Artikel enthaltenen Bilder und sonstiges Drittmaterial unterliegen ebenfalls der genannten Creative Commons Lizenz, sofern sich aus der Abbildungslegende nichts anderes ergibt. Sofern das betreffende Material nicht unter der genannten Creative Commons Lizenz steht und die betreffende Handlung nicht nach gesetzlichen Vorschriften erlaubt ist, ist für die oben aufgeführten Weiterverwendungen des Materials die Einwilligung des jeweiligen Rechteinhabers einzuholen. Weitere Details zur Lizenz entnehmen Sie bitte der Lizenzinformation auf http://creativecommons .org/licenses/by/4.0/deed.de.

\section{References}

Anit S (2006) The effects of leadership style and team process on performance and innovation in functionally heterogeneous teams. $\mathrm{J}$ Manag 32(1):132-157

Aslan S, Diken A, Sendogdu AA (2011) Investigation of the effects of strategic leadership on strategic change and innovativeness of SMEs in a perceived environmental uncertainity. Proced Soc Behav Sci 24:627-642

Bandura A (1993) Perceived self-efficacy in cognitive development and functioning. Educ Psychol 28(2):117-148

Bandura A (1997) Self-efficacy: the exercise of control. Macmillan, New York, $p 1997$

Barber LK, Munz DC, Bagsby PG, Grawitch MJ (2009) When does time perspective matter? Self-control as a moderator between time perspective and academic achievement. Personal Individ Differ 46(2):250-253. https://doi.org/10.1016/j.paid.2008.10.007

Bass B (1998) Transformational leadership: industrial, military, and educationalimpact. Lawrence Erlbaum Associates, Mahwah

Bass BM, Avolio BJ (1994) Improving organizational effectiveness through transformational leadership. Sage Publications, New York

Bass BM, Avolio BJ (1995) Multifactor leadership questionnaire: leader form, rater form, and scoring key for MLQ. Mind Garden, Redwood City
Blomgren AS, Svahn K, Åström E, Rönnlund M (2016) Coping strategies in late adolescence: relationships to parental attachment and time perspective. J Genet Psychol 177(3):85-96. https://doi. org/10.1080/00221325.2016.1178101

Bandura A (1996) Regulation of cognitive processes through perceived self-efficacy. In: Jennings GH, Belanger D (eds) Passages beyondthe gate: A Jungian approach to understanding the nature of American psychology at the dawn of the new millennium. Needham Heights, MA, pp 96-107

Bass BM (1981) Stogdill's handbook of leadership. New York, Macmillan

Bass BM, Avolio BJ (1990) Transformational Leadership Development: Manual for the Multifactor Leadership Questionnaire. Palo Alto, CA: Consulting Psychologists Press.

Boniwell I, Zimbardo P (2003) Time to find the right balance. Psychologist 1:1

Boniwell I, Osin EN, Sircova A (2014) Introducing time perspective coaching: a new approach to improve time management and enhance well-being. Int J Evid Based Coach Mentor 12(2):24-40

Bono JE, Anderson MH (2005) The advice and influence networks of transformational leaders. J Appl Psychol 90:1306-1314

Chemers MM, Watson CB, May ST (2000) Dispositional affect and leadership effectiveness: a comparison of self-esteem, optimism, and efficacy. Pers Soc Psychol Bull 26:267-277

Drake L, Duncan E, Sutherland F, Abernethy C, Henry C (2008) Time perspective and correlates of wellbeing. Time Soc 17(1):47-61. https://doi.org/10.1177/0961463X07086304

Einarsen S, Aasland MS, Skogstad A (2007) Destructive leadership behaviour: a definition and conceptual model. Leadersh Q 18(3):207-216. https://doi.org/10.1016/j.leaqua.2007.03.002

Epel ES, Bandura A, Zimbardo PG (1999) Escaping homelessness: the influences of self-efficacy and time perspective on coping with homelessness. J Appl Soc Psychol 29(3):575-596. https://doi. org/10.1111/j.1559-1816.1999.tb01402.x

Felfe J, Goihl K (2002) Deutsche überarbeitete und ergänzte Version des Multifactor Leadership Questionnaire (MLQ) [German revised and extended version of the Multifactor Leadership Questionnaire (MLQ)]. In A. Glöckner-Rist (Ed.). ZUMA-Informationssystem. Elektronisches Handbuch sozialwissenschaftlicher Erhebungsinstrumente. Version 5.00. Zentrum für Umfragen Methoden und Analysen, Mannheim

Fitzgerald S, Schutte NS (2010) Increasing transformational leadership through enhancing self-efficacy. J Manage Dev 29(5):495-505. https://doi.org/10.1108/02621711011039240

Gonzalez A, Zimbardo PG (1985) Time in perspective: a psychology today survey report. Psychol Today 1:21-26

Goodnight R (2004) Laissez-faire leadership. Econ J 98(392):820-823

Gutiérrez-Braojos C (2015) Future time orientation and learning conceptions: effects on metacognitive strategies, self-efficacy beliefs, study effort and academic achievement. Educ Psychol Int J Exp Educ Psychol 35(2):192-212. https://doi.org/10.1080/01443 410.2013 .858101

Hayes AF (2013) Introduction to mediation, moderation, and conditional process analysis: a regression-based approach. Guilford Press, New York

Holman EA, Zimbardo PG (2009) The social language of time: the time perspective-social network connection. Basic Appl Soc Psychol 31(2):136-147. https://doi.org/10.1080/01973530902880415

Judge TA, Bono JE (2000) Five-factor model of personality and transformational leadership. J Appl Psychol 85:751-765

Kane TD, Zaccaro SJ, Tremble TR, Masuda AD (2002) An examination of the leaders regulation of groups. Small Group Res 33(1):65-120. https://doi.org/10.1177/104649640203300103

Kirkpatick SA, Locke EA (1991) Leadership: do traits matter? Acad Manag Exec 5(2):48-60 
Korff J, Biemann T, Voelpel SC (2017) Human resource management systems and work attitudes: the mediating role of future time perspective. J Organ Behav 38(1):45-67

Maurer TJ (2001) Career-relevant learning and development, worker age, and beliefs about self-efficacy for development. J Manage 27:123-140

Murphy J (1992) The landscape of leadership preparation: reframing the education of school administrators. Corwin, Newbury

Northouse PG (2004) Leadership: theory and practice. Sage, Thousand Oaks

Northouse PG (2016) Leadership: theory and practice, 7th edn. Sage, Thousand Oaks

Olivera-Figueroa LA, Juster R, Morin-Major JK, Marin M, Lupien SJ (2015) A time to be stressed? Time perspectives and cortisol dynamics among healthy adults. Biol Psychol 111:90-99. https:// doi.org/10.1016/j.biopsycho.2015.09.002

Paglis LL, Green SG (2002) Leadership self-efficacy and managers' motivation for leading change. J Organ Behav 23(2):215-235. https://doi.org/10.1002/job.137

Papastamatelou J, Unger A (2018) Differences in burnout proneness depend on time perspective- evidence from an occupational sample of industrial employees and MBA-students. Dialogues Clin Neurosci Mental Health 1:52-57. https://doi.org/10.26386/obrel a.v1i1.8

Papastamatelou J, Unger A, Giotakos O, Athanasiadou F (2015) Is time perspective a predictor of anxiety and perceived stress? Some preliminary results from Greece. Psychol Stud 60(4):468-477. https://doi.org/10.1007/s12646-015-0342-6

Quigley NR (2003) The relationship between leader core selfevaluations, team feedback, leader efficacy, transformational leadership, team efficacy, team goals, team action and transition processes, and team performance, $\mathrm{Ph}$.D. dissertation, University of Maryland

Reuschenbach B, Funke J, Drevensek AM, Ziegler N (2011) Testing a German version of the zimbardo time perspective inventory (ZTPI). Annales Universitatis Paedagogicae Cracoviensis 152:16-29

Rönnlund M, Carelli MG (2018) Deviations from a balanced time perspective in late adulthood: associations with current $\mathrm{g}$ and $\mathrm{g}$ in youth. Intelligence. https://doi.org/10.1016/j.intell.2018.09.002

Rönnlund M, Åström E, Adolfsson R, Carelli MG (2018) Perceived stress in adults aged 65 to 90: relations to facets of time perspective and COMT val158Met polymorphism. Front Psychol 9:378. https://doi.org/10.3389/fpsyg.2018.00378

Schwarzer R, Jerusalem M (1995) Generalized self-efficacy scale. In: Weinman J, Wright S, Johnston M (eds) Measures in health psychology: a user's portfolio causal and control beliefs. Nfer-Nelson, Windsor, pp 35-37
Stewart J (2006) Transformational leadership: an evolving concept examined through the works of burns, bass, Avolio, and Leithwood. Can J Educ Adm Policy 54:1-29

Stolarski M (2016) Not restricted by their personality: balanced time perspective moderates well-established relationships between personality traits and well-being. Personal Individ Differ 101:518 519. https://doi.org/10.1016/j.paid.2016.05.314

Stolarski M, Bitner J, Zimbardo PG (2011) Time perspective, emotional intelligence and discounting of delayed awards. Time Soc 20(3):346-363

Stolarski M, Vowinckel J, Jankowski KS, Zajenkowski M (2016) Mind the balance, be contented: balanced time perspective mediates the relationship between mindfulness and life satisfaction. Personal Individ Differ 93:27-31. https://doi.org/10.1016/j. paid.2015.09.039

Taylor J, Wilson JC (2019) Using our understanding of time to increase self-efficacy towards goal achievement. Psychol Med Heliyon. https://doi.org/10.1016/j.heliyon.2019.e02116

Turner EE, Rejeski WJ, Brawley LR (1997) Psychological benefits of physical activity are influenced by the social environment. J Sport Exerc Psychol 19:119-130

Uçara AC, Erenb E, Erzenginc E (2012) Determination of the relationship between leadership perceptions of blue collars and organizational outcomes by using MLQ analysis. Proced Soc Behav Sci 41:196-208

Unger A, Yan J, Busch R (2019) The relationship between the Zimbardo time perspective inventory and violations of business ethics in China: unbalanced time perspective increases the acceptance of unethical business behavior. Time Soc 28(1):83-106

Wisner MD (2011) Psychological strengths as predictors of effective student leadership. Christ High Educ 10(3-4):353-375. https:// doi.org/10.1080/15363759.2011.576223

Wojtkowska K, Stolarski M, Matthews G (2019) Time for work: Analyzing the role of time perspectives in work attitudes and behaviors. Curr Psychol. https://doi.org/10.1007/s12144-019-00536-y

Zebardast A, Besharat MA, Hghighatgoo M (2011) The relationship between self-efficacy and time perspective in students. Proced Soc Behav Sci 30:935-938. https://doi.org/10.1016/j.sbspr o.2011.10.181

Zimbardo PG, Boyd JN (1999) Putting time into perspective: a valid, reliable individual-differences metric. J Pers Soc Psychol 77(6):1271-1288. https://doi.org/10.1037/0022-3514.77.6.1271

Zimbardo PG, Boyd JN (2008) The time paradox: the new psychology of time that will change your life. Free Press, New York

Zimbardo PG, Sword RM, Sword RKM (2012) The time cure: overcoming PTSD with the new psychology of time perspective therapy. Jossey-Bass, San Francisco 